\title{
Research into linear vibration welding of glass fibre-reinforced nylon 66
}

\author{
HENRY GRANJON PRIZE 2014 Winner Category A: Joining and Fabrication Technology
}

\author{
Aleksandra Weglowska
}

Received: 5 June 2014 / Accepted: 3 November 2014 /Published online: 18 November 2014

(C) The Author(s) 2014

\begin{abstract}
In this paper, results of vibration welding of glass fibre-reinforced nylon 66 are presented. The hot air blower was used for preheating of the welded surfaces before the welding process. The aim of the research was determination of the influence of the thermal conditions of vibration welding process on the quality of joints, including weld microstructure, the content of the crystal phase, orientation of the glass fibres in the weld and the tensile strength. Influence of the welding conditions on the weld microstructure and the orientation of the glass fibres was determined during the light microscopic examinations as well as in the scanning electron microscopic examinations. A melting temperature and the content of the crystal phase of welds were tested using differential scanning calorimetry (DSC). Fitting of the mathematical function describing penetration curve was performed, and calculations of the heat power were made. Comparison of results of vibration welding of nylon composite conducted with and without preheating was carried out. Results indicate that the use of preheating during vibration welding process eliminates the solid-state friction in the welding process and leads to the significant improvement of the welds quality at the shorter weld time.
\end{abstract}

Keywords Vibration · Welding · Heating · Air · Glass · Polyamides

Doc. IIW-2515, recommended for publication by Commission XVI "Polymer Joining and Adhesive Technology."

A. Węlowska $(\bowtie)$

Department of Resistance and Friction Welding and Environmental

Engineering, Instytut Spawalnictwa (Institute of Welding),

Gliwice 44-100Bł. Czesława 16-18, Poland

e-mail: aleksandra.weglowska@is.gliwice.pl

\section{Introduction}

Vibration welding is commonly used in the automotive, medical, electrotechnical industry and in the production of components used in everyday life [1]. The first studies and analysis on the process of vibration welding of thermoplastics were conducted by Stokes [2, 3], who has divided the process into four characteristic phases: I-solid friction, II-unsteady state of friction, III—-steady state meltdown and IV—cooling and solidification under pressure. Simple analytical models for estimating the influence of welding parameters on the transitions of the weld zone are used by scientists to evaluate the welding process of different types of thermoplastics [4-8]. Investigations of the influence of the welding parameters, especially weld pressure and amplitude on the quality of joints made of different kinds of nylon [9-11] as well as in different configurations of nylon [12, 13] were published in many scientific publications.

During welding with high weld pressure (4.0 MPa), a narrow weld is created and glass fibres are parallel oriented with the welding direction, which influences the low mechanical properties of joints [9]. It was also highlighted that low weld pressure $(0.5 \mathrm{MPa})$ is beneficial for the quality of joints because it allows to achieve wide weld. This effect is positive because glass fibres have a possibility to be introduced perpendicularly into the weld and penetrate it, which increases the joint's tensile strength $[4,5,9]$ as well as fatigue strength $[14,15]$.

The other trend in the field of vibration welding is application of preheating of the joining interfaces in order to melt the thin film of plastic at welded interface before the beginning of the welding process. It allows the reduction of abrasion and fine fluff. For preheating, various heat sources can be used, including the following: coil heaters, IR radiators, lasers and hot air blowers [16].

Investigations which were conducted in the field of vibration welding with preheating, using the infrared radiators, 
concerned determination of the preheating influence on the reduction of abrasion, amount of the fine fluff in the welding area, melt film thickness at preheated surfaces and on the tensile strength of joints [17-19].

Scientists emphasised that preheating of the samples' surface influences the wider width of the melt film in the welding area and thereby the higher tensile strength of joints $[18,19]$.

Results indicate that in order to precisely analyse the welding process, monitoring and registration of the run of the welding parameters are necessary $[2,6,20]$. The nature of the process allows the monitoring of the following variables: a welding amplitude, a weld pressure, a penetration and a shear force. In practice, monitoring the run of penetration and shear force is used. Using the special monitoring devices, it is possible to control the welding process [6]. It should be noted that the measurements of nonconventional signals are also useful in case of welding processes such as arc welding [21, 22].

This paper aims to provide new insight into understanding the phenomena occurring during vibration welding of glass fibre-reinforced nylon 66. The main goal of the current research is to determine the influence of the thermal conditions of vibration welding process on the quality of joints including weld microstructure, the content of the crystal phase, orientation of the glass fibres in the welding area and the mechanical strength. During investigation, a measuring device for monitoring the run of the welding parameters was used.

\section{Experimental setup}

Investigations were carried out at Instytut Spawalnictwa in Gliwice on the vibration welding stand, equipped with a linear vibration welding machine (M-112H). During the welding process, the samples vibrate with a constant frequency $n$ of $240 \mathrm{~Hz}$. The amplitude of vibration $a$ is in the range of 0.7 to $1.8 \mathrm{~mm}$. Short welding time $t_{w}$ (max to $9.9 \mathrm{~s}$ ) decides on the productivity of the process. The welding pressure $p_{w}$ is established up to $2560 \mathrm{~N}$. Welding stand was also equipped with the measurement system VibRecord designed at Instytut Spawalnictwa, which records the runs of: amplitude, penetration and welding pressure.

Preheating was conducted using a $1600 \mathrm{~W}$ hot air blower supplied from Leister. The maximum hot air temperature is up to $550{ }^{\circ} \mathrm{C}$. A two-mouth nozzle with a $10.0 \times 16.5 \mathrm{~mm}$ dimension was used, which permitted simultaneous preheating of two welding surfaces. The distance between the nozzle and the surfaces of the sample was $2.0 \mathrm{~mm}$. Handling in the holder enabled insertion and ejection of the blower in the preheating area with to-and-fro motion. Welding stand is shown in Fig. 1.

Vibration welding with preheating was conducted in the following way. After setting up the welding parameters and preheating time, the air blower was inserted between the welding samples. After surfaces were preheated at the appropriate time, the blower was ejected and the welding process began. During studies, low weld pressure and low value of amplitude were used in order to limit extrusion of the preheated material from the samples' surfaces outside the joint. Using an infrared camera, the temperature of the plastic material on the surface of the bottom sample was measured immediately after ejecting the hot blower from the preheating area. The emission factor was taken as 0.85 . Exemplary views of thermograms are shown in Fig. 2.

The material used in this research was TECAMID 66 GF30 (30\% glass fibre-reinforced nylon 66). Properties of nylon composite are given in Table 1.

\section{Investigation methodology}

Investigations were carried out using butt welding of samples of dimensions: $10.0 \times 33.0 \times 56.0 \mathrm{~mm}$. Samples were oriented in the tool in such a way that the $10.0 \times 33.0 \mathrm{~mm}$ surface became the welding area. Time welding module was used. Welding parameters are set in Table 2.
Fig. 1 Welding stand (a): 1, vibration welding machine; 2 , tooling with samples; 3 , vibration head with the down tool; 4 , control system; 5, VibRecord measurement system; b hot air blower with marked movement of the blower
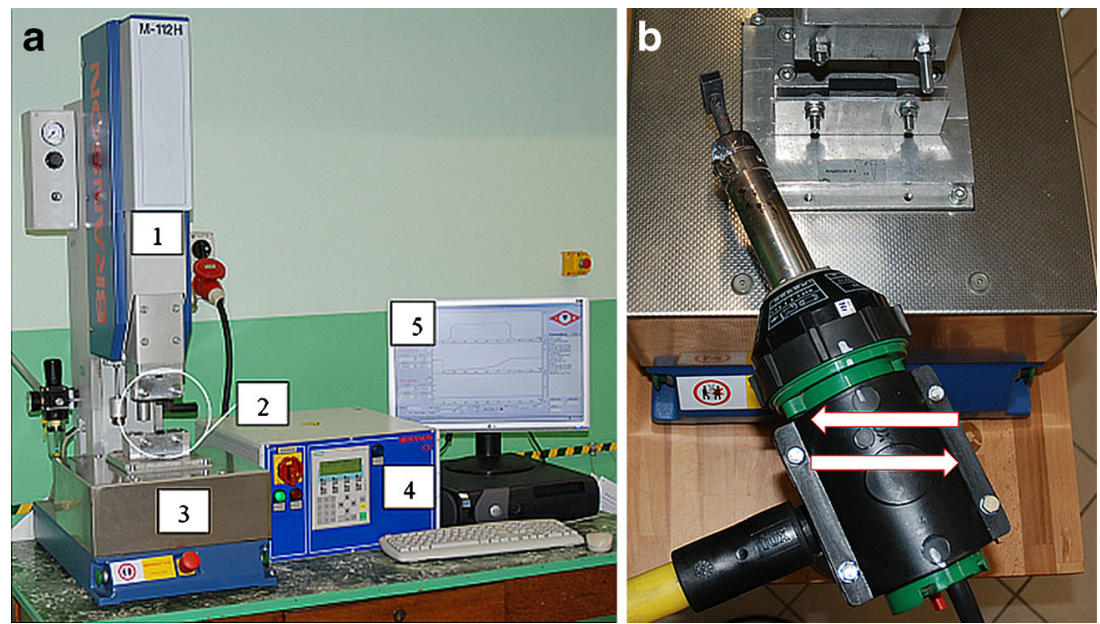
a

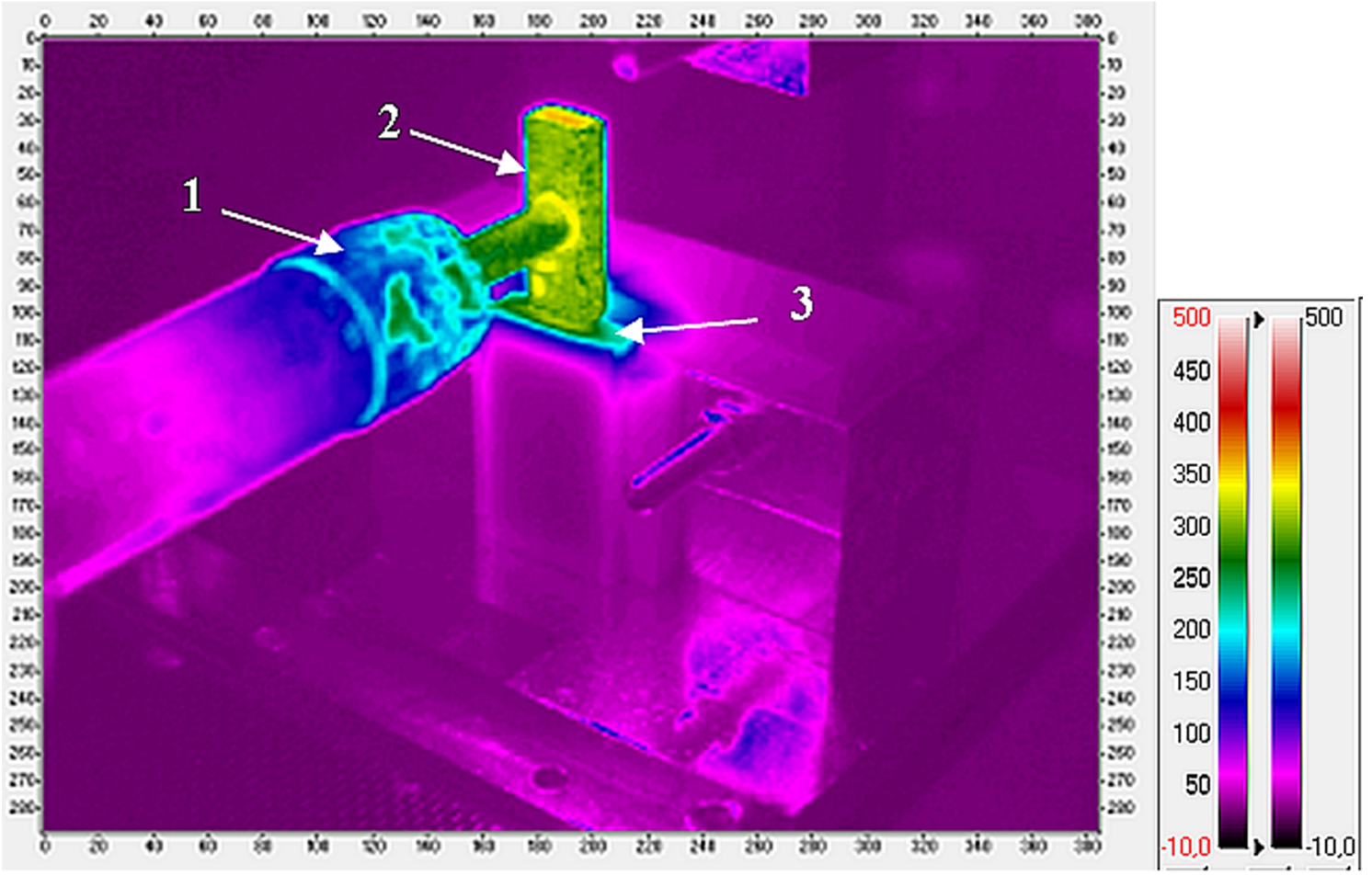

b

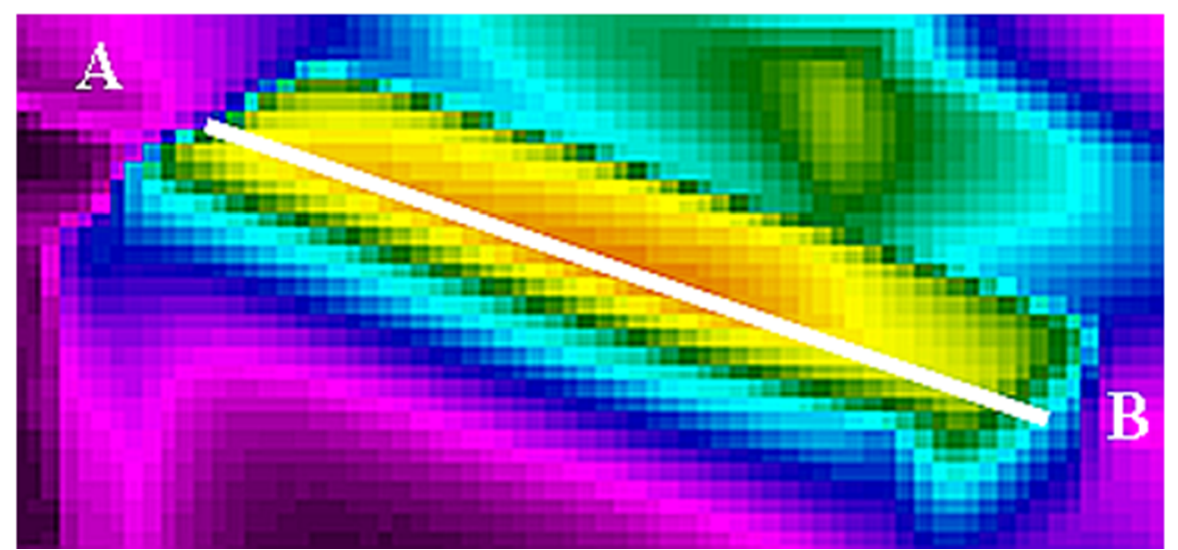

Fig. 2 View of thermograms: a preheating process: 1, hot air blower; 2, two mouth nozzle; 3, bottom preheated surface; $\mathbf{b}$ bottom preheated surface of the sample with the marked measurement line A-B

Vibration welding with the preheating was conducted. Preheating in the vibration welding process permits not only for the reduction or elimination of the first phase of the process (solid state) and a brittle flash, but it can also be useful in increasing the quality of joints. The aim of this part of the study was to determine the influence of the thermal conditions of the preheating process on the weld's structure, crystal phase content and orientation of glass fibres in a weld. An infrared camera was used to measure the temperature of the material on the bottom sample's surface. Welding conditions used during welding with the preheating are set in Table 3 .

In case of two types of welding processes, for each set of welding parameters, three joints were made. Investigations on the impact of welding conditions on the changes in the structure of plastic in the welding area were conducted using light microscopy examinations in the polarised reflected light-Leica MeF4M. The aim of examinations was to determine the influence of thermal conditions on the welds' structure, the welds' width and orientation of glass fibres in the weld. Examinations using the scanning electron microscope NEON 40EsB CrossBeam were conducted in order to determine the influence of thermal conditions on the direction and orientation of glass fibres and on the fractures of joint after the tensile test. Using differential scanning calorimetry (DSC), the melting temperature and degree of crystal phase in welds were determined. DSC investigations were done using apparatus Phox 200 of NETZSCH company. Samples for tests were cut out using a microtome. Mechanical properties of joints were 
Table 1 Properties of nylon composite [23]

\begin{tabular}{lllll}
\hline Density $\left(\mathrm{g} / \mathrm{cm}^{3}\right)$ & $\begin{array}{l}\text { Tensile strength at } \\
\text { break }(\mathrm{MPa})\end{array}$ & $\begin{array}{l}\text { Elongation at } \\
\text { break }(\%)\end{array}$ & $\begin{array}{l}\text { Crystalline melting } \\
\text { temperature }\left({ }^{\circ} \mathrm{C}\right)\end{array}$ & $\begin{array}{l}\text { Degree of } \\
\text { crystallisation }(\%)\end{array}$ \\
\hline 1.35 & $\approx 87.0$ & 1.52 & $260-265$ & 16.58 \\
\hline
\end{tabular}

determined during the tensile test, carried out at the INSTRON 4210 with a tensile test speed of $20 \mathrm{~mm} / \mathrm{min}$.

During welding, the character of friction changes from the Coulomb friction in solid-state phase (PI) to the viscous friction in steady-state phase (PIII). Exemplary run of amplitude and penetration as the function of time is shown in Fig. 3.

In order to define the thermal conditions of vibration welding, connected directly with the welding parameters, it was necessary to calculate the heat power of the process. Findings were used for analysing further the influence of the thermal conditions on the quality of joints. The heat power in PI was calculated according to the following formula [3]:

$P_{P I}=\frac{2 \cdot p_{w} \cdot f \cdot v_{f} \cdot S}{\pi}, \mathrm{W}$

where:

$f \quad$ Coefficient of friction, 0.3

$p_{w} \quad$ Weld pressure $(\mathrm{MPa})$

$v_{f} \quad$ Friction velocity $(\mathrm{m} / \mathrm{s})$

$S \quad$ Cross-section area of weld $\left(\mathrm{m}^{2}\right)$

Table 2 Set of the welding parameters

\begin{tabular}{|c|c|c|c|c|c|}
\hline \multicolumn{6}{|c|}{ Weld pressure } \\
\hline \multicolumn{2}{|c|}{$p_{w}=1.35 \mathrm{MPa}$} & \multicolumn{2}{|c|}{$p_{w}=2.58 \mathrm{MPa}$} & \multicolumn{2}{|c|}{$p_{w}=3.87 \mathrm{MPa}$} \\
\hline$a(\mathrm{~mm})$ & $t_{w}(\mathrm{~s})$ & $a(\mathrm{~mm})$ & $t_{w}(\mathrm{~s})$ & $a(\mathrm{~mm})$ & $t_{w}(\mathrm{~s})$ \\
\hline \multirow[t]{5}{*}{1.0} & 4.5 & 1.0 & 4.5 & 1.0 & 4.5 \\
\hline & 5.5 & & 5.5 & & 5.5 \\
\hline & 6.0 & & 6.0 & & 6.0 \\
\hline & 6.5 & & 6.5 & & 6.5 \\
\hline & 7.0 & & 7.0 & & - \\
\hline \multirow[t]{5}{*}{1.2} & 5.5 & 1.2 & 3.5 & 1.2 & 3.5 \\
\hline & 6.0 & & 4.0 & & 4.0 \\
\hline & 6.5 & & 4.5 & & 4.5 \\
\hline & 7.0 & & 5.0 & & 5.0 \\
\hline & 7.5 & & 5.5 & & 5.5 \\
\hline \multirow[t]{5}{*}{1.6} & 4.0 & 1.6 & 2.5 & 1.6 & 2.0 \\
\hline & 4.5 & & 3.0 & & 2.5 \\
\hline & 5.0 & & 3.5 & & 3.0 \\
\hline & 5.5 & & 4.0 & & 3.5 \\
\hline & 6.0 & & - & & - \\
\hline
\end{tabular}

Friction velocity $v_{f}$ was calculated according to the relationship [4]:

$v=a \cdot n, \mathrm{~m} / \mathrm{s}$

where:

$$
\begin{array}{ll}
a & \text { Amplitude (mm) } \\
n & \text { Frequency, } \\
& 240 \mathrm{~Hz}
\end{array}
$$

It was important to know how long the first phase lasted $\left(t_{\mathrm{PI}}\right)$. The calculations were done in accordance with the following equation [4]:

$t_{P I}=\frac{\Pi}{\alpha} \cdot\left[\frac{\kappa\left(T_{m}-T_{a}\right)}{4 \cdot f \cdot p_{w} \cdot n \cdot a}\right]^{2}, \quad \mathrm{~s}$

where:

$\kappa \quad$ Thermal conductivity, $0.21 \mathrm{~W} / \mathrm{m}^{\circ} \mathrm{C}$

$T_{\mathrm{m}} \quad$ Melt temperature, $265^{\circ} \mathrm{C}$

$T_{\text {a }} \quad$ Ambient temperature, $23^{\circ} \mathrm{C}$

$\alpha \quad$ Heat transfer coefficient, $0.083 \mathrm{~mm}^{2} / \mathrm{s}$

The heat power in the third phase was calculated according to the following formula [1]:

$P_{\mathrm{PIII}}=\frac{\mu \cdot S \cdot v_{f}^{2}}{4 \cdot h}, \mathrm{~W}$

where:

$\mu \quad$ Newtonian viscosity

\begin{tabular}{|c|c|c|c|}
\hline \multicolumn{2}{|c|}{$\begin{array}{l}\text { Welding } \\
\text { parameters }\end{array}$} & \multicolumn{2}{|l|}{ Preheating conditions } \\
\hline$a(\mathrm{~mm})$ & $t_{w}(\mathrm{~s})$ & Temperature of hot air $T_{\mathrm{ha}}\left({ }^{\circ} \mathrm{C}\right)$ & Preheating time $t_{p}(\mathrm{~s})$ \\
\hline 1.0 & $6.0 ; 7.0$ & 350 & 60.0 \\
\hline \multirow[t]{2}{*}{1.2} & $4.5 ; 5.5$ & 450 & 30.0 \\
\hline & & 550 & 15.0 \\
\hline
\end{tabular}

Table 3 Set of the welding parameters used during welding with the preheating 


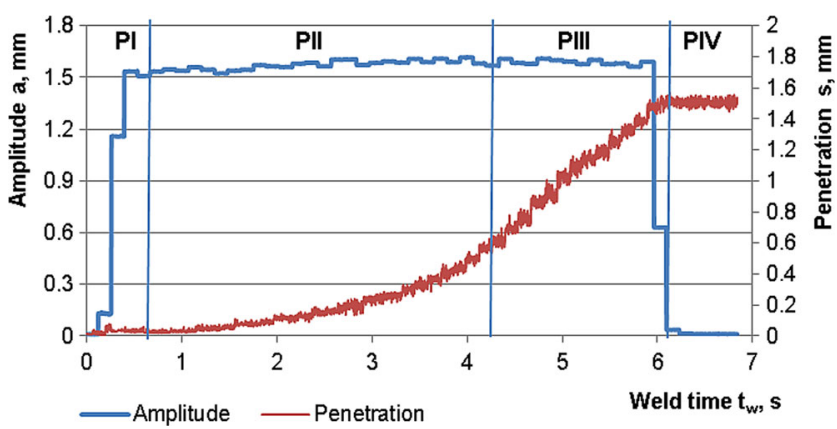

Fig. 3 Exemplary run of amplitude and penetration as the function of time. $p_{w}=1.35 \mathrm{MPa}, a=1.0 \mathrm{~mm}$. $P I$ the solid-state phase, $P I I$ the nonsteady-state phase, $P I I I$ the steady-state phase, $P I V$ the cooling phase

$h$ Thickness of the layer of plasticized material in the third phase (PIII; m).

Value $\mu$ depends on the weld pressure. For $p_{w}=3.87 \mathrm{MPa}$, $\mu=29.5(\mathrm{~N} \cdot \mathrm{s}) / \mathrm{m}^{2}$; for $p_{w}=2.58 \mathrm{MPa}, \mu=30.1(\mathrm{~N} \cdot \mathrm{s}) / \mathrm{m}^{2}$; for $p_{w}=1.35 \mathrm{MPa}, \mu=30.8(\mathrm{~N} \cdot \mathrm{s}) / \mathrm{m}^{2}[4]$.

In order to calculate the heat power in PIII, it was necessary to calculate thickness of the layer $h$ according to the relationship [4]:

$h=\sqrt[3]{\frac{2 \cdot \mu \cdot v_{p} \cdot b^{2}}{p_{w}}}, \mathrm{~mm}$

where:

$v_{p}$ Penetration velocity $(\mathrm{mm} / \mathrm{s})$

$b$ Thickness of sample, $10.0 \mathrm{~mm}$.

Based on analysis of the penetration runs, registered using the VibRecord, it was possible to calculate the value of penetration velocity $v_{p}$. For each set of welding parameters, three joints were made and three penetration runs were registered. Exemplary runs of the penetrations as the function of time are presented in Fig. 4.

For each three recorded runs, one common penetration curve was determined. The next step was to conduct the fitting function. Common penetration curves were circumscribed with the polynomial functions of the second degree as in Fig. 5.

Based on the analysis of the penetration runs, the beginning of the third phase was determined. At the beginning and in the next few seconds of this phase, derivatives of the polynomial functions of the second degree were calculated (value of $\operatorname{tg} \alpha$ ), which determine the penetration velocity $v_{p}$. Then, it was possible to calculate the thickness of the layer of plasticized material $h$ and then the heat power $P_{\mathrm{PIII}}$. It was assumed that the heat power at the beginning and the end of phase PII were equal to the heat power at the end of the phase PI and at the beginning of the phase PIII, respectively.

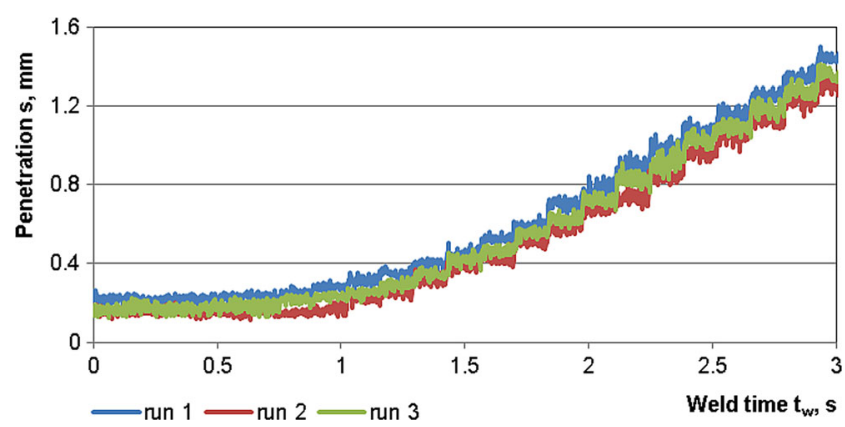

Fig. 4 Exemplary runs of penetrations as the function of time

Runs of the heat power in the three phases were circumscribed with the mathematical functions. Exemplary runs of the heat power welding process are shown in Fig. 6.

Calculations of the heat power were also carried out for the vibration welding conducted with the preheating. Based on analysis of the penetration runs, it was found that the first phase did not occur. Exemplary run of the amplitude and penetration as the time function is shown in Fig. 7.

Because of the lack of the first phase and presence of the plasticized layer of material on the welding surfaces, the heat power in the entire welding process was calculated as in the phase PIII according to Eq. (4). Exemplary results of calculations are shown in Fig. 8.

\section{Results of vibration welding}

\subsection{Microscopy examinations}

Results of microscopic examinations of selected joints and for different welding parameters are shown in Figs. 9, 10 and 11. Results of fractography examinations (SEM) of selected joints are shown in Fig. 12a, b.

\subsection{Differential scanning calorimetry}

Results of DSC are set in Table 4. Exemplary melting curve established for the welding area is shown in Fig. 13.

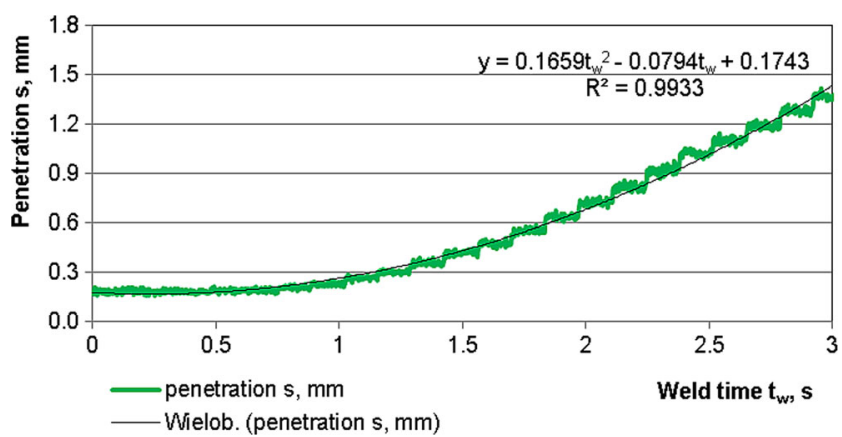

Fig. 5 Exemplary common penetration curve as the function of time circumscribed with the polynomial function 
Fig. 6 Influence of the weld time on the heat power change during the welding process with two amplitudes of welding: $a=1.0$ and $1.6 \mathrm{~mm} . p_{w}=1.35 \mathrm{MPa}$. PI the solid-state phase, $P I I$ the nonsteady-state phase, PIII the steady-state phase

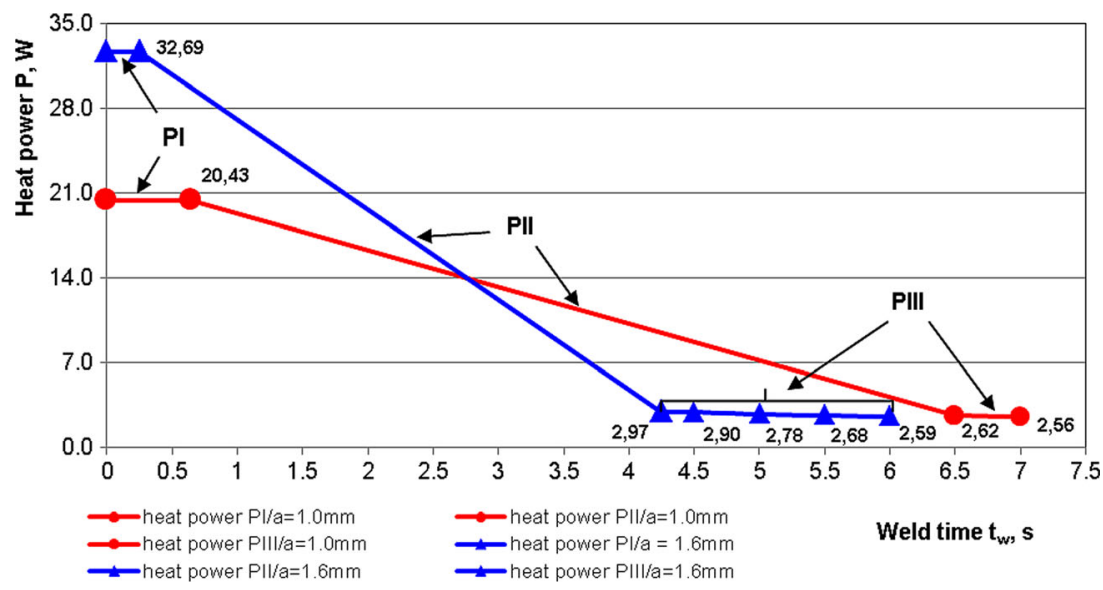

\subsection{Tensile test}

Based on the tensile test results, the average value of tensile strength $R_{m}$ and the standard deviation $\sigma$ were calculated. Results are presented in Fig. 14.

\subsection{Analysis of results of the conventional vibration welding}

Heat power generation proceeds rapidly. The largest amount of heat is generated during the first phase, and as the layer of plasticized material occurs in the welding area in phase PIII and gets wider, the heat power decreases. The presence of the phase PIII determines the quality of the joints.

The analysis of results of the microscopy examinations shows that glass fibres in all welds accumulate in the welding area, which is connected with the shortening of the elements during welding and also with the flow direction of the plasticized material. Glass fibres in the welding area, mainly in the middle of the sample, are oriented with the direction of the flow of the plasticized material into the flash, which is visible as single

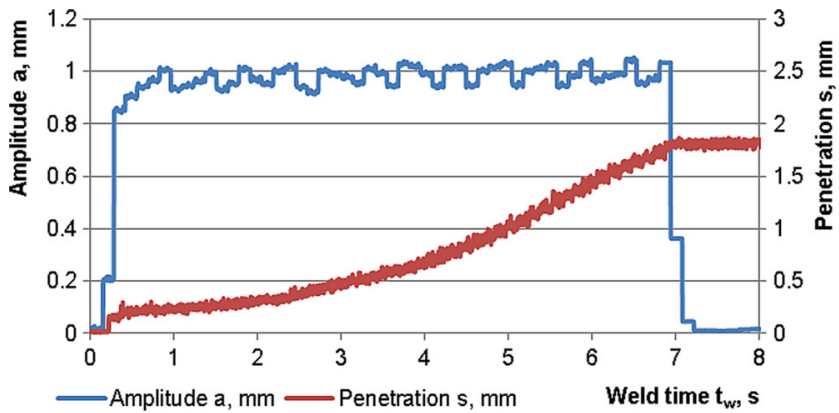

Fig. 7 Influence of the weld time on penetration's runs. Welding conditions: $T_{\mathrm{ha}}=550{ }^{\circ} \mathrm{C}, t_{p}=15.0, a=1.0 \mathrm{~mm}, t_{w}=7.0 \mathrm{~s}$ "points" (Fig. 8b). At the edge of the sample, they are mainly oriented parallel to the welding direction and visible as thin, short "lines" (Fig. 8a). Some of the glass fibres are introduced into the weld at different angles. Transition between the parent material and the weld is clearly visible. The width of weld depends on the thermal conditions connected with the welding parameters. For the specified amplitude, the lower is the weld pressure, the longer is the weld time and the wider is the width of weld (Table 4).

Results on the way glass fibres accumulated and oriented in the welding area were confirmed in the SEM of fractures. The tensile test revealed that the fracture is fragile (Fig. 11).

Results of the DSC for all joints showed that the melting temperature of the material in the weld is similar to the melting temperature of the parent material. It was noticed that the degree of crystallisation of welds is in the range of 4.8-9.6\% (Table 4). The content of the crystal phase depends on the amplitude, the weld pressure and heat power connected with them. The highest content of the crystal phase occurred during welding with an amplitude of $1.6 \mathrm{~mm}$ (for all $p_{w}$ ), when the heat power is high. The lowest content was observed during welding with an amplitude of $1.0 \mathrm{~mm}$ and a low weld pressure at $1.35 \mathrm{MPa}$. The low content of the crystal phase is connected with the rapid cooling of the welding area (about $70{ }^{\circ} \mathrm{C} / \mathrm{s}$ ) and accumulation of the glass fibres in the weld, which limit spherulites' growth.

Welding parameters influence the tensile strength of joints. Joints made with low welding parameters and with low content of the crystal phase in welds were characterised by low tensile strength, about $36.0 \mathrm{MPa}$. Results also indicate that the higher the weld pressure is and/or the amplitude, the greater is the heat power and 
Fig. 8 Influence of the weld time on the heat power change in the steady-state phase (PIII) during welding with preheating with two amplitudes of welding: $a=1.0$ and $1.2 \mathrm{~mm} ; p_{w}=1.35 \mathrm{MPa}$

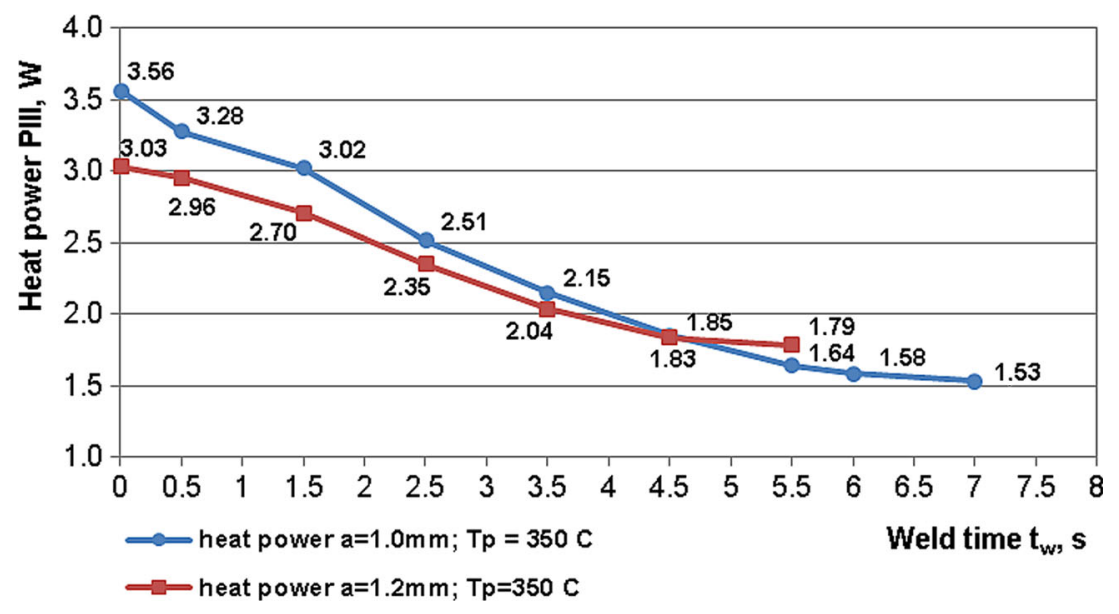

the shorter the weld time required in achieving a high quality of joints (Fig. 13). Joints with the highest content of the crystal phase are characterised by strength in the range of $65-77 \mathrm{MPa}$, which constitute up to $89 \%$ of the strength of the base material.

\section{Results of vibration welding with preheating}

Results of the average temperature measured at the preheated surface are set in Table 5 .

\subsection{Microscopy examinations}

Results of microscopy examinations are shown in Figs. 15, 16 and 17. The widths of welds were marked with arrows. Results of weld widths measurements are set in Table 6.

Results of fractography examinations (SEM) of selected joint are shown in Fig. 18.

\subsection{Differential scanning calorimetry}

Results of DSC are set in Table 6 as well as the results of weld width measurements.

\subsection{Tensile test}

Based on the tensile test results, the average value of tensile strength $R_{m}$ and the standard deviation $\sigma$ were calculated. Results are presented in Fig. 19.

\subsection{Analysis of results of the vibration welding} with preheating

Based on the results of microscopy examinations of joints, it was found that preheating process has a positive influence on the weld structure and an orientation of the glass fibres in the welding area. Between the parent material and weld there is a very soft transition, especially at the edge of weld (Fig. 15a, b). Preheating influences also the weld width, which is almost two times wider than in joints made only by vibration welding (Table 6). Welds were wider when low

Fig. 9 Microstructure of weld: a the edge and $\mathbf{b}$ the middle. $p_{w}=$ $1.35 \mathrm{MPa}, a=1.0 \mathrm{~mm}, t_{w}=7.0 \mathrm{~s}$. The width of weld is marked with an arrow
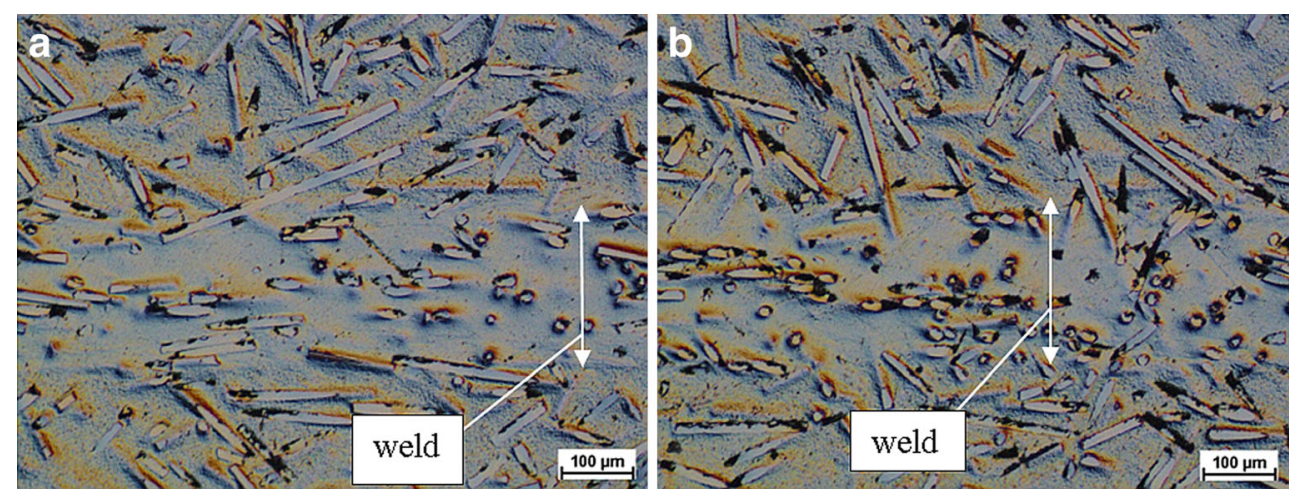
Fig. 10 Microstructure of weld: $\mathbf{a}$ the edge and $\mathbf{b}$ the middle. $p_{w}=$ $1.35 \mathrm{MPa}, a=1.6 \mathrm{~mm}, t_{w}=6.0 \mathrm{~s}$. The width of weld is marked with an arrow
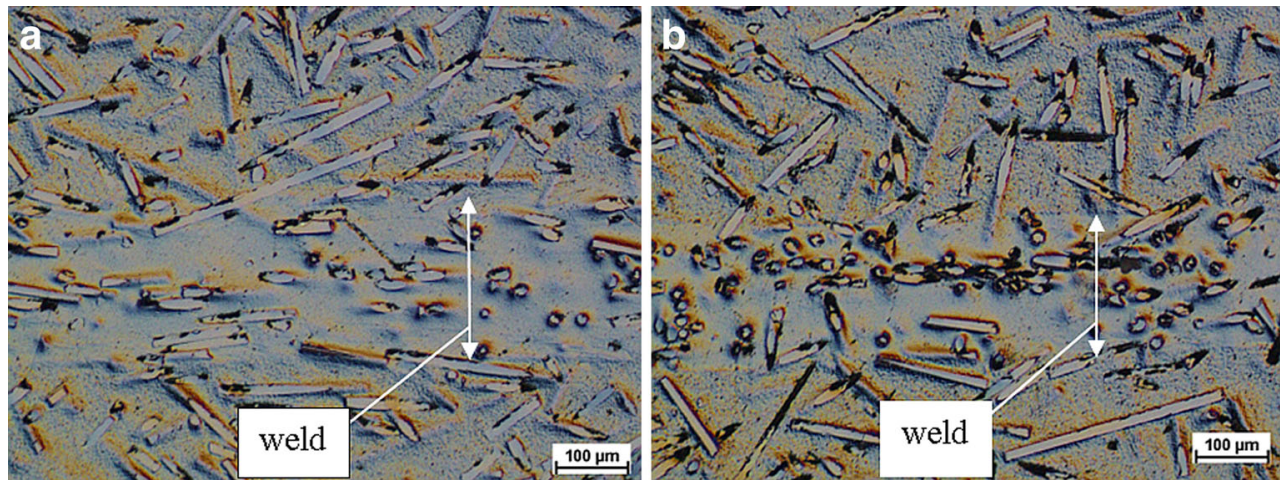

temperature $\left(350\right.$ and $450{ }^{\circ} \mathrm{C}$ ) of hot air and short weld time were applied. There is a concentration of the glass fibres in the welding area, but simultaneously it was noticed that many glass fibres are introduced to the welding area perpendicularly to the weld direction (Figs. 15c and 17c). Such orientation and wide weld had positive influence on the joint strength.

The content of the crystal phase was lower than in the parent material and amounted up to $10.52 \%$ (Table 6), which is $63 \%$ of the value of the parent material. In case of lower hot air at 350 and $450{ }^{\circ} \mathrm{C}$, longer preheating time was required at 60.0 and $30.0 \mathrm{~s}$, respectively. These preheating conditions and low amplitudes $(1.0$ and $1.2 \mathrm{~mm})$ result in a wider width of welds. Long preheating time also results in a not so rapid cooling of the welding area, which is why these joints are characterised by the highest content of the crystal phase.

Although the content of the crystal phase in the joints was lower than in the parent material, the tensile strength of joints was very high, close to the parent material. The highest strength about $86.5-86.9 \mathrm{MPa}$ was obtained when the temperature of the hot air was 350 and $450{ }^{\circ} \mathrm{C}$, at amplitudes of $a=1.0$ and $1.2 \mathrm{~mm}$ (Fig. 19). These joints are characterised by wide welds and high content of the crystal phase, 8.57-10.52\%. The lowest strength of joints was achieved when a $550{ }^{\circ} \mathrm{C}$ temperature of hot air and low amplitude $(a=$ $\left.1.0 \mathrm{~mm}\left(R_{m} \approx 50.0 \mathrm{MPa}\right)\right)$ were applied.

Perpendicular orientation of the glass fibres to the welding area may influence the high strength of joints. Glass fibres have higher strength than the matrix. It was also found that in the middle of the sample the matrix around the fibres is characterised by the ductile fracture, which might have influenced the high joint strength (Fig. 18).

The amount of heat introduced to the weld as the effect of friction is very low and will depend on the temperature of the hot air and the preheating time. These parameters influence the thickness of the plasticized layer as well as on the heat power of the process.

\section{Summary}

Based on the comparison of results of vibration welding conducted with and without preheating, it was found that in the vibration welding process, heat generation depends on the presence of first-phase and solid-state friction. The
Fig. 11 Microstructure of weld: a the edge and $\mathbf{b}$ the middle. $p_{w}=$ $3.87 \mathrm{MPa}, a=1.6 \mathrm{~mm}, t_{w}=3.5 \mathrm{~s}$. The width of weld is marked with an arrow
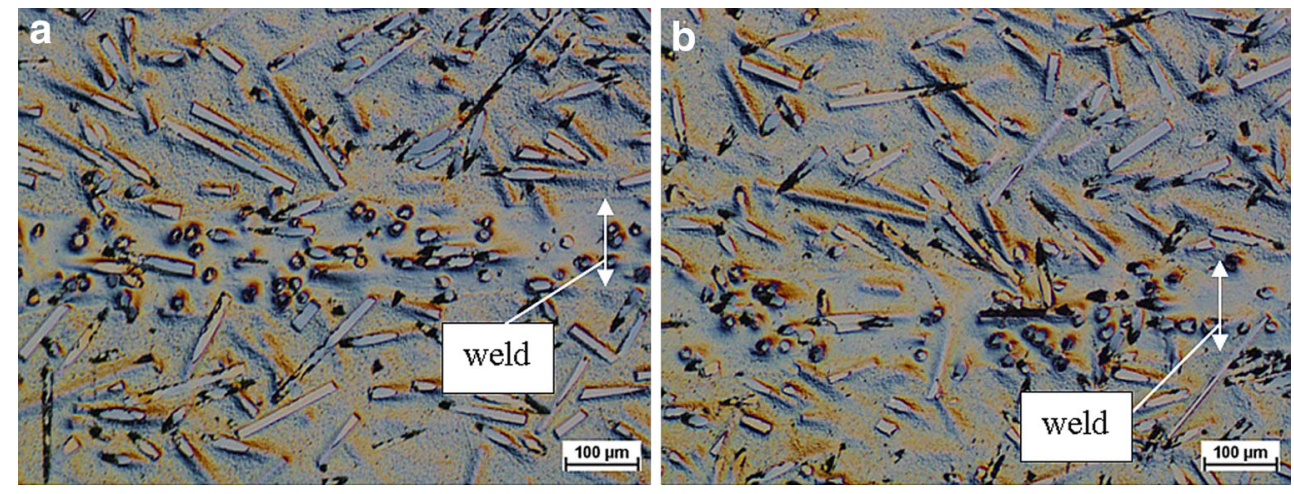

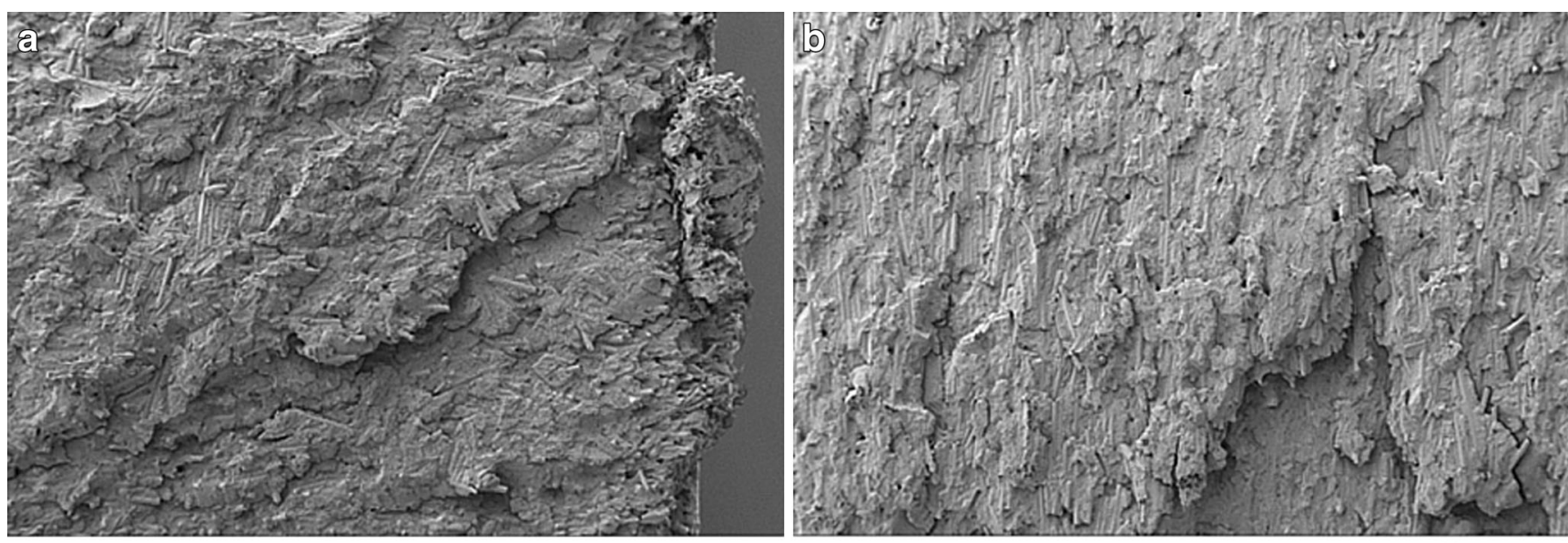

Date: $\quad$ Signal A $=S E 2 \mathrm{Mag}=50 \mathrm{X}$

$100 \mathrm{rm}$

Dato: $\quad$ Signal $A=$ SE2 Mag $=50 \mathrm{X}$

$100 \mathrm{~mm}$

Fig. 12 Fracture of sample's surface: a the edge and $\mathbf{b}$ the middle. $p_{w}=1.35 \mathrm{MPa}, a=1.2 \mathrm{~mm} ; t_{w}=6.5 \mathrm{~s}$

Table 4 Set of results of DSC and weld width $s_{w}$ measurements

Fig. 13 Exemplary melting curve. $p_{w}=1.35 \mathrm{MPa}, a=1.0 \mathrm{~mm}$, $t_{w}=7.0 \mathrm{~s}$

\begin{tabular}{|c|c|c|c|c|c|}
\hline \multicolumn{3}{|c|}{ Welding parameters } & \multirow[t]{2}{*}{$s_{w}(\mathrm{~mm})$} & \multirow[t]{2}{*}{ Melting temperature $\left({ }^{\circ} \mathrm{C}\right)$} & \multirow[t]{2}{*}{ Degree of crystallisation (\%) } \\
\hline$p_{w}(\mathrm{MPa})$ & $a(\mathrm{~mm})$ & $t_{w}(\mathrm{~s})$ & & & \\
\hline \multirow[t]{3}{*}{1.35} & 1.0 & 7.0 & 0.22 & 258.1 & 4.80 \\
\hline & 1.2 & 6.0 & 0.17 & 258.6 & 7.10 \\
\hline & 1.6 & 6.0 & 0.19 & 259.7 & 8.82 \\
\hline \multirow[t]{3}{*}{2.58} & 1.0 & 6.0 & 0.17 & 258.6 & 8.33 \\
\hline & 1.2 & 5.5 & 0.15 & 259.1 & 8.52 \\
\hline & 1.6 & 4.0 & 0.15 & 258.6 & 9.60 \\
\hline \multirow[t]{3}{*}{3.87} & 1.0 & 6.5 & 0.12 & 258.6 & 8.57 \\
\hline & 1.2 & 4.5 & 0.14 & 258.8 & 8.27 \\
\hline & 1.6 & 3.5 & 0.13 & 258.6 & 9.19 \\
\hline
\end{tabular}

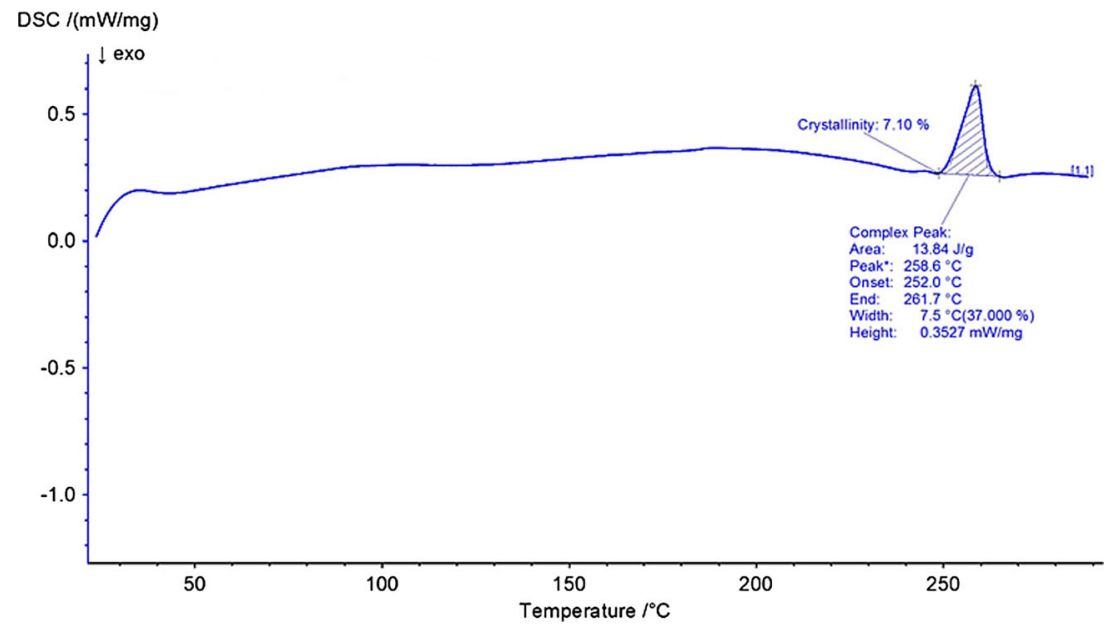


Fig. 14 Influence of the weld time on the tensile strength at different weld pressure and amplitudes: a $a=1.0 \mathrm{~mm}, \mathbf{b} a=$ $1.2 \mathrm{~mm}$ and $\mathbf{c} a=1.6 \mathrm{~mm}$
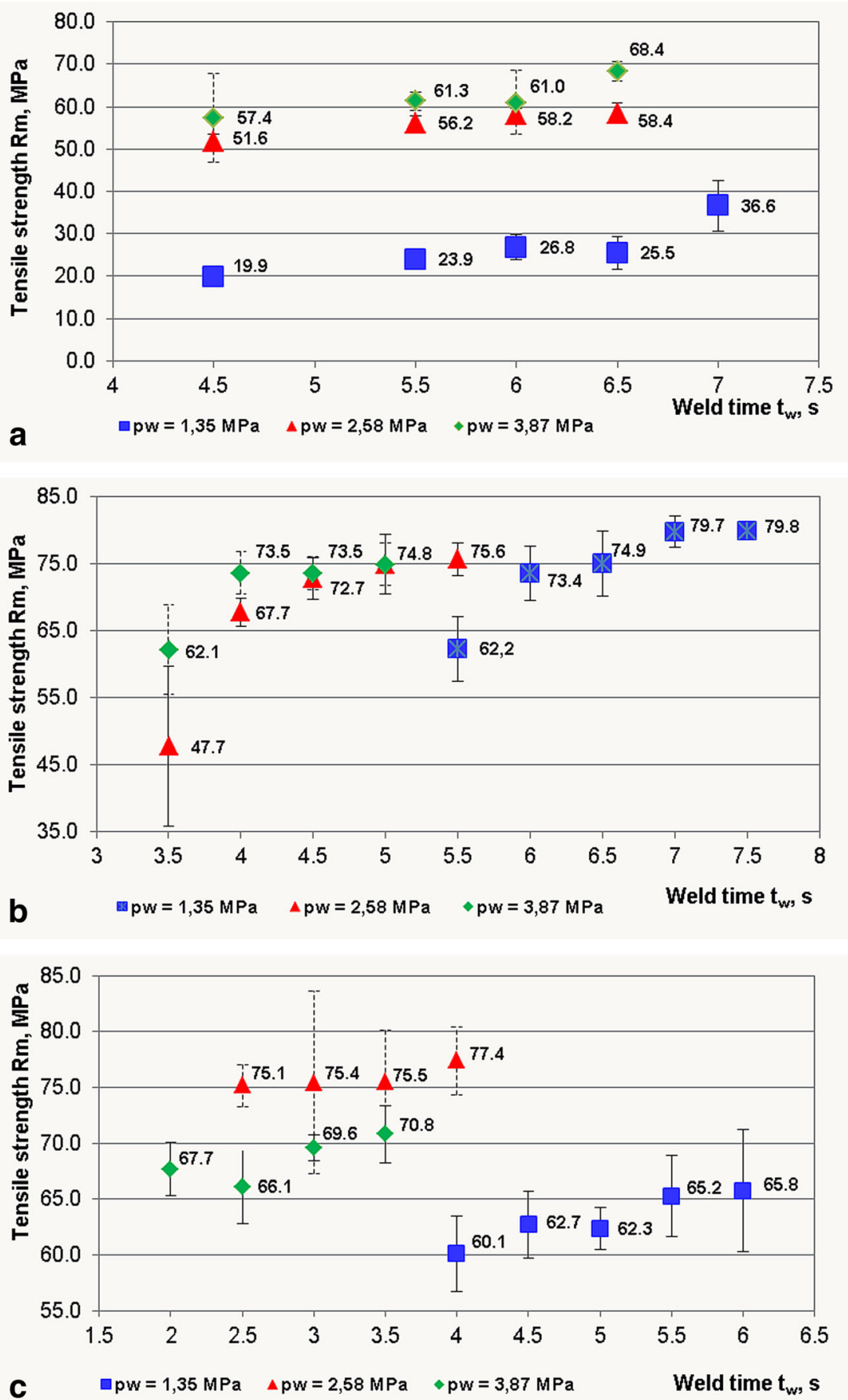

Table 5 Results of average temperature measurements

Preheating conditions

$T_{\text {ha }}\left({ }^{\circ} \mathrm{C}\right) \quad t_{p}(\mathrm{~s})$

\begin{tabular}{lll}
\hline 350 & 60.0 & $\approx 225$ \\
450 & 30.0 & $\approx 250$ \\
550 & 15.0 & $\approx 245$ \\
\hline
\end{tabular}

amount of heat introduced into the weld is connected with the welding parameters, especially weld pressure and amplitude. In the process realised with preheating, the amount of heat introduced into the weld depends on the temperature of hot air and the preheating time. In both cases, good quality of joints is achieved if the layer of plasticized material is being created in the welding area.

Heat power in the conventional welding process is very high at the beginning of the first phase, and when 
Fig. 15 Macrostructure (a) and microstructures of the welding area: fragment $\mathrm{A}(\mathbf{b})$ and fragment $\mathrm{B}(\mathbf{c}) . a=1.0 \mathrm{~mm}, t_{w}=6.0 \mathrm{~s}, T_{\mathrm{ha}}=$ $350{ }^{\circ} \mathrm{C}, t_{p}=60.0 \mathrm{~s}$. The width of weld is marked with an arrow
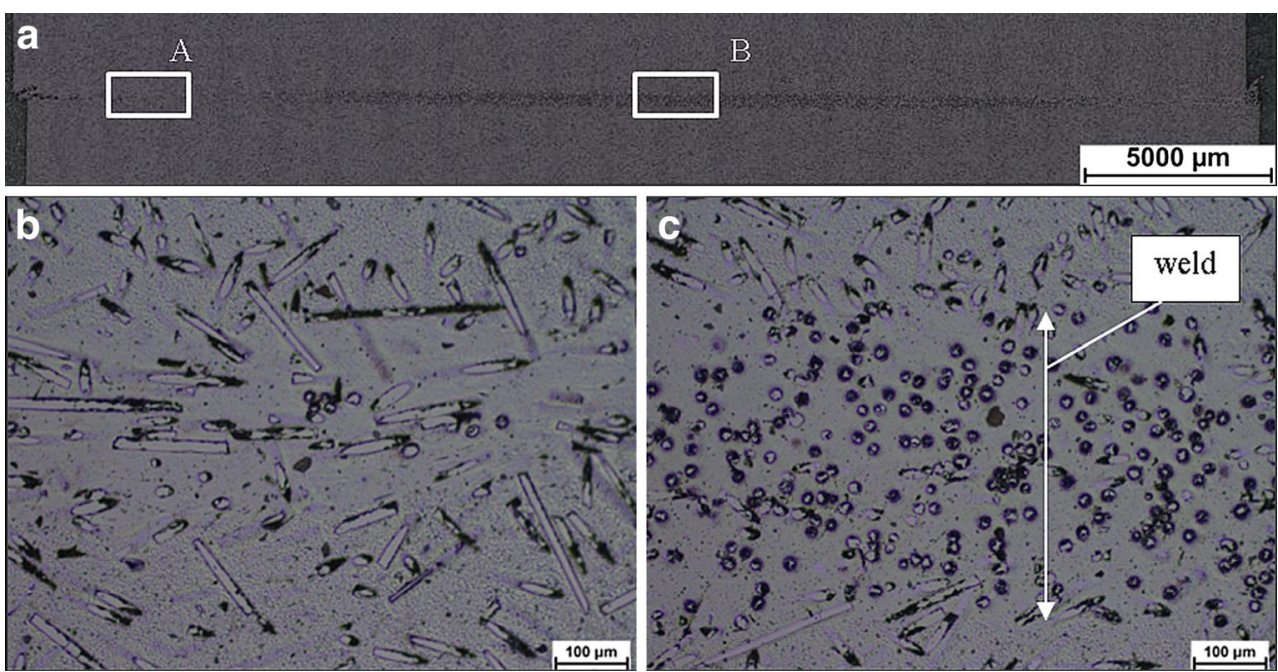

the plasticized layer of material occurs in the weld zone, the heat power decreases rapidly to a few watts (Fig. 5). In case of vibration welding with preheating at the beginning of the welding process, the heat power amounts a few watts, because of the presence of a layer of plasticized material on the welding surfaces before vibrations start. As the welding process proceeds, heat power decreases very slowly (Fig. 7).

Glass fibres in both cases are accumulated in the welding area, which influences decrease of the content of the crystal phase in the weld zone. Orientation of the glass fibres in the welds is also similar. Differences occur when transition between parent material and welding area is compared. When surfaces of the samples are preheated, this transition becomes almost invisible (Figs. 16c and 17c), which influences the ductile fracture of the samples in the tensile test and higher strength of joints (Fig. 18).

The content of the crystal phase for both types of processes was lower than in the parent material (Tables 4 and 6) but was higher for welds made with the preheating and with the same amplitude and weld pressure $\left(p_{w}=1.35 \mathrm{MPa}\right)$ than in process realised without preheating. The lower content of the crystal phase in joints made without preheating results in narrower welds and rapid cooling of the weld zone, which amount to about $70{ }^{\circ} \mathrm{C} / \mathrm{s}$ and because of glass fibres accumulation in the weld. In case of joints made with preheating, welds were two times wider.

Preheating of the material at the surfaces to be welded influences positively the run of the welding process - the solid-state phase (PI) does not occur, which eliminates formation of the brittle flash and increases the quality of joints (Fig. 6). Application of preheating allows to achieve higher strength of joints to the value corresponding to the parent material (87 MPa) in shorter weld time (Fig. 19b). If the preheating is not used, the maximum tensile strength of joints is about $80 \mathrm{MPa}$ (Fig. 13b). It was also found
Fig. 16 Macrostructure (a) and microstructures of the welding area: fragment $\mathrm{A}(\mathbf{b})$ and fragment B (c). $a=1.2 \mathrm{~mm}, t_{w}=4.5 \mathrm{~s}, T_{\mathrm{ha}}=$ $350{ }^{\circ} \mathrm{C}, t_{p}=60.0 \mathrm{~s}$. The width of weld is marked with an arrow
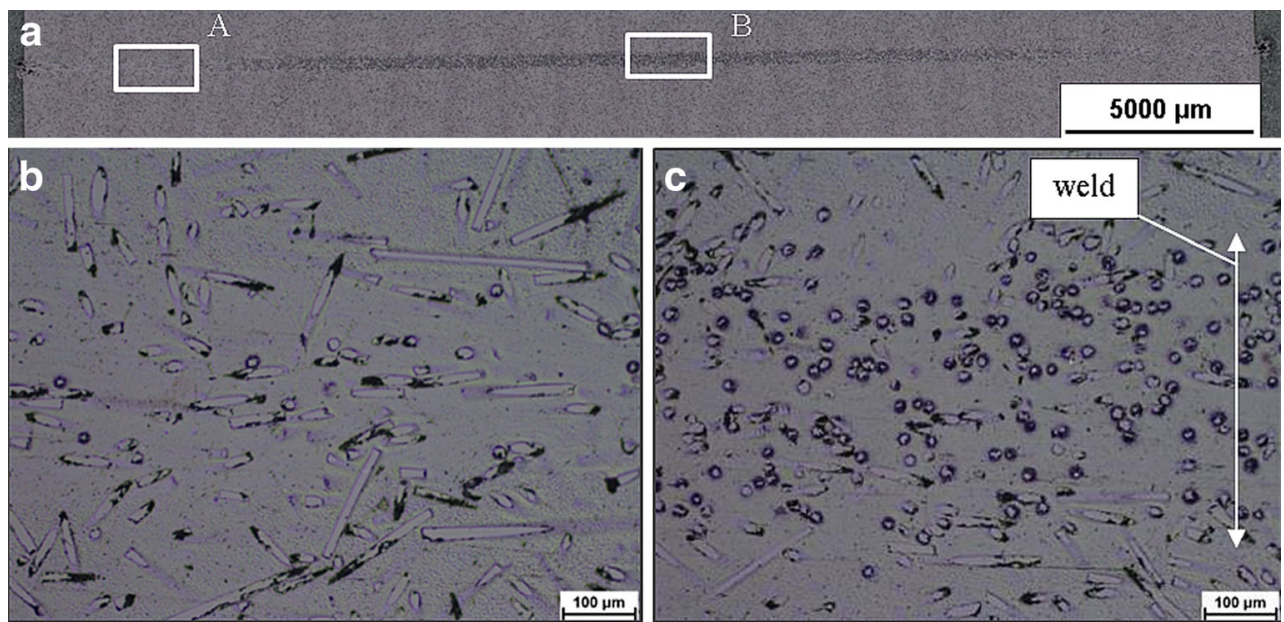
Fig. 17 Macrostructure (a) and microstructures of the welding area: fragment $\mathrm{A}(\mathbf{b})$ and fragment B (c). $a=1.2 \mathrm{~mm}, t_{w}=4.5 \mathrm{~s}, T_{\mathrm{ha}}=$ $550{ }^{\circ} \mathrm{C}, t_{p}=15.0 \mathrm{~s}$. The width of weld is marked with an arrow
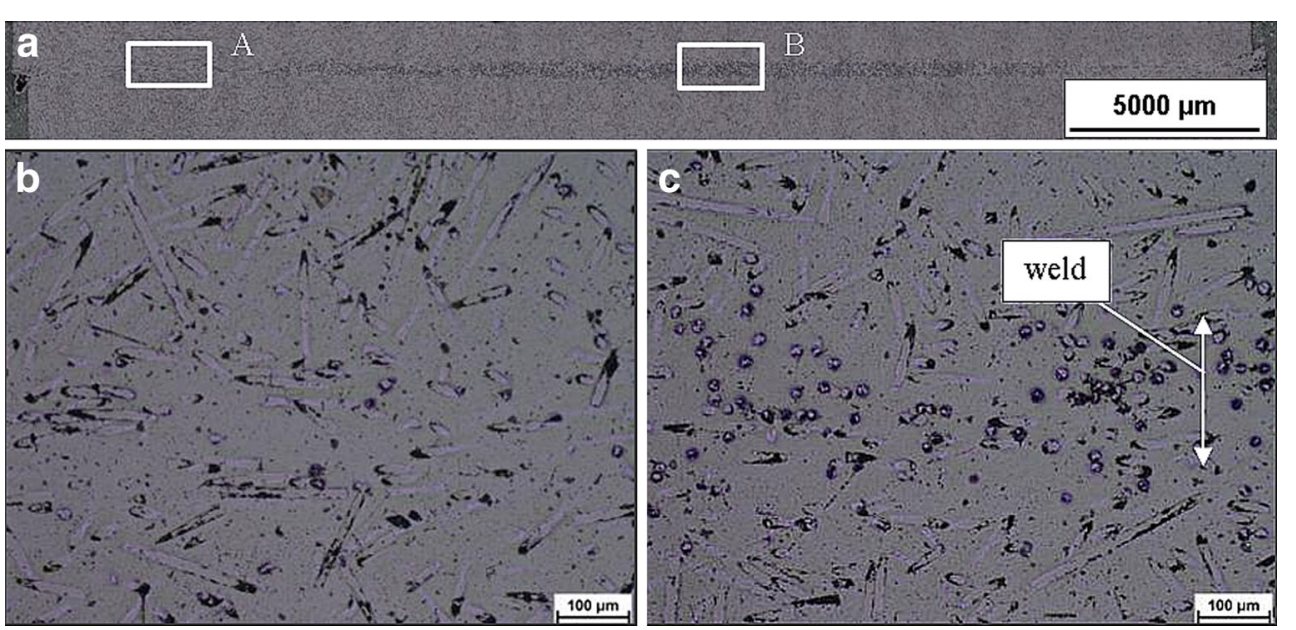

\begin{tabular}{|c|c|c|c|c|c|c|}
\hline \multicolumn{4}{|c|}{ Welding conditions } & \multirow[t]{2}{*}{$s_{w}(\mathrm{~mm})$} & \multirow[t]{2}{*}{ Melting temperature $\left({ }^{\circ} \mathrm{C}\right)$} & \multirow[t]{2}{*}{ Degree of crystallisation (\%) } \\
\hline$a(\mathrm{~mm})$ & $t_{w}(\mathrm{~s})$ & $T_{\text {ha }}\left({ }^{\circ} \mathrm{C}\right)$ & $t_{p}(\mathrm{~s})$ & & & \\
\hline \multirow[t]{3}{*}{1.0} & 6.0 & 350 & 60.0 & 0.41 & 259.5 & 9.19 \\
\hline & & 450 & 30.0 & 0.26 & 259.3 & 10.52 \\
\hline & & 550 & 15.0 & 0.25 & 258.4 & 8.60 \\
\hline \multirow[t]{3}{*}{1.2} & 4.5 & 350 & 60.0 & 0.45 & 258.9 & 8.57 \\
\hline & & 450 & 30.0 & 0.34 & 258.9 & 8.78 \\
\hline & & 550 & 15.0 & 0.22 & 259.2 & 8.13 \\
\hline
\end{tabular}

Table 6 Set of results of DSC and weld widths $s_{w}$ measurements

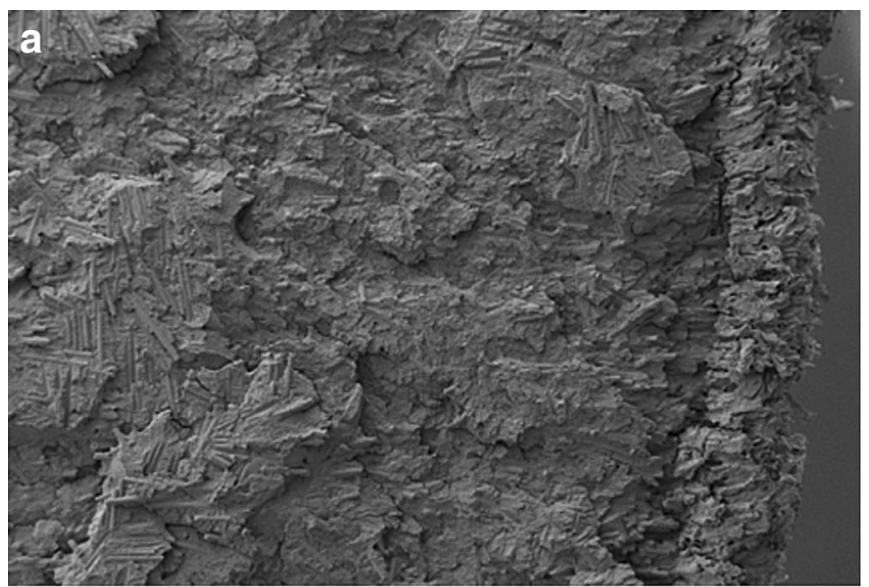

Date: $\quad$ Signal $A=S E 2$ Mag $=50 \mathrm{X}$ $E H T=3.00 \mathrm{kV} \quad W D=6.1 \mathrm{~mm}$

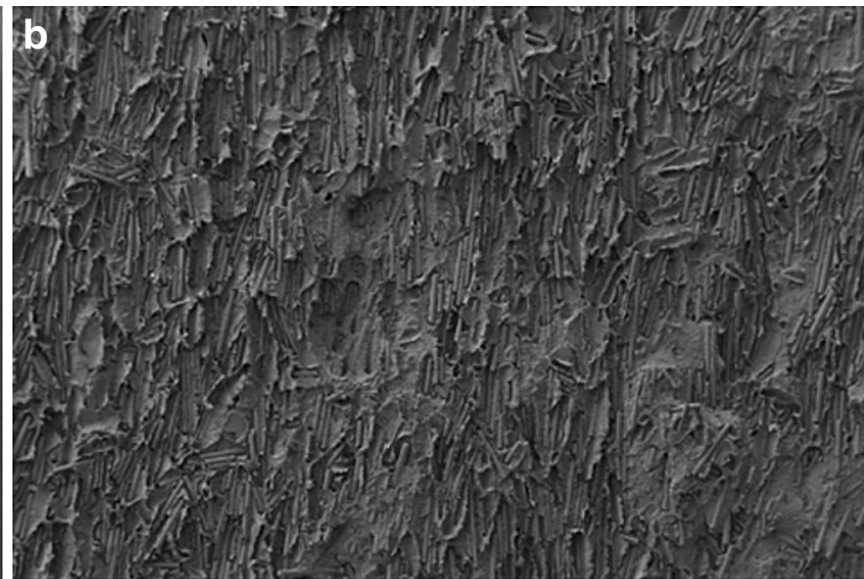

Date: $\quad$ Signal $A=S E 2$ Mag $=50 X$ EHT $=3.00 \mathrm{kV}$ WD $=6.1 \mathrm{~mm}$ $\stackrel{100 \mu \mathrm{m}}{1}$

Fig. 18 Fracture of sample's surface: a the edge and $\mathbf{b}$ the middle. $a=1.2 \mathrm{~mm}, t_{w}=5.5 \mathrm{~s}, T_{\mathrm{ha}}=550{ }^{\circ} \mathrm{C}, t_{p}=15.0 \mathrm{~s}$ 
Fig. 19 Influence of the temperature of the hot air $T_{\text {ha }}$ on the tensile strength of joints: a $a=$ $1.0 \mathrm{~mm}$ and $\mathbf{b} a=1.2 \mathrm{~mm}$
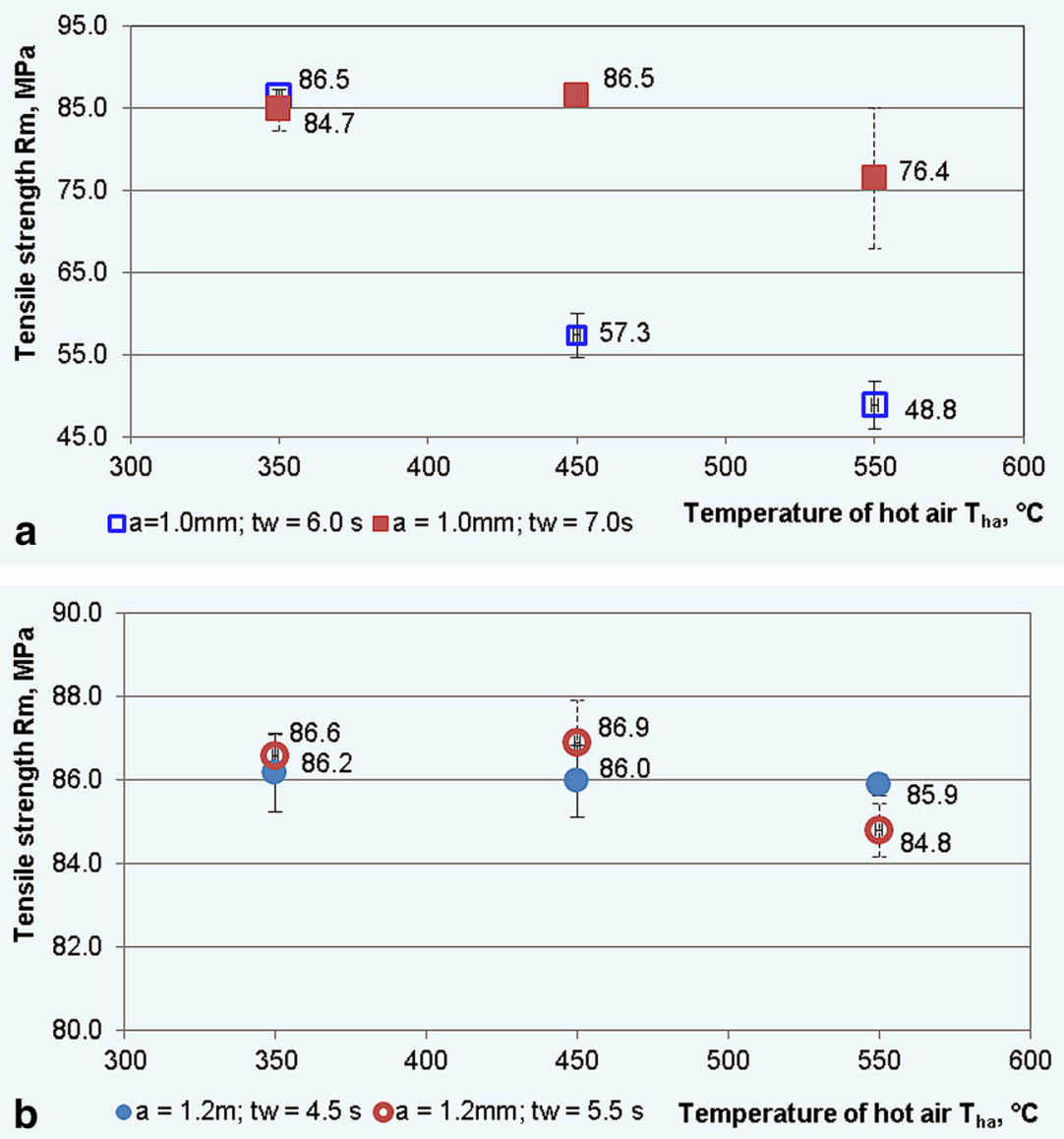

that repeatability of results obtained from the tensile test was much higher than in case of welding without preheating.

\section{Conclusions}

- In order to achieve the high quality of joints, the third phase of the process has to occur as well as the layer of plasticized material in the welding area has to be formed.

- Heat power in the vibration welding process depends on the welding parameters. The higher the amplitude and/or the weld pressure, the higher is the heat power and the shorter is the weld time necessary to achieve the high quality of joints.

- Tensile strength of joints depends on the content of the crystal phase of weld.

- The maximum content of the crystal phase in joints made without preheating was $9.6 \%$, and the maximum tensile strength was about $80 \mathrm{MPa}$. In welds made with preheating, the content of the crystal phase amounts up to $10.52 \%$ and the tensile strength of joints was about $87 \mathrm{MPa}$ (close to the parent material).

- Preheating eliminates the solid-state phase in the welding process, through the creation of a thin layer of plasticized material, directly before the beginning of welding. Heat power generated through friction is very low.

- In comparison to the process of vibration welding, preheating with the hot air influences positively on the weld structure. Transition between the parent material and weld is very soft; there is a lack of structural notch.

- In both types of processes, glass fibres accumulate in the welding area and orient according to the direction of vibrations and with the flow of the plasticized material into the flash.

- Accumulation of the glass fibres in the weld and rapid cooling of the welding area reduce the content of the crystal phase in welds. 
Acknowledgements Research presented in this paper was performed within the framework of the scientific project no. 2011/01/N/ST8/07213, financed by the National Science Centre, Poland.

\section{References}

1. Grewell DA, Benatar A, Park JB (2003) Plastics and composites welding handbook. Carl HanserVerlag, Munich

2. Stokes VK (1988) Welding of thermoplastics. Part I: phenomenology of the welding process. Polym Eng Sci 28:718-727. doi:10.1002/ pen. 760281104

3. Stokes VK (1988) Vibration welding of thermoplastics. Part II: analysis of the welding process. Polym Eng Sci 28:728-739. doi: 10.1002/pen.760281105

4. Bates PJ, MacDonald J, Sidiropoulos V, Kontopoulou M (2005) Comparison of experimental and analytical vibration welding of meltdown - time profiles for nylon 66 and polypropylene. Polym Eng Sci 45:789-797. doi:10.1002/pen.20333

5. Kamal MR, Chung YM, Gomez R (2008) Three-dimensional fiber orientation in vibration welded joints of glass fiber reinforced polyamide - 6. Polym Compos 29:954-963. doi:10.1002/pc.20530

6. PathamB FPH (2011) Thermoplastic vibration welding: review of process phenomenology and processing-structure-property interrelationship. Polym Eng Sci 51:1-22. doi:10.1002/pen.21784

7. Patham B, Foss PH (2012) Estimation of melt film variables during the steady-state penetration phase of thermoplastic vibration welding using generalized Newtonian fluid model. Polym Eng Sci 52:581597. doi:10.1002/pen.22121

8. Patham B, Foss PH (2014) A simple analytical model for estimation of melt film variables in thermoplastic vibration welding. Polym Eng Sci 54:499-511. doi:10.1002/pen.23506

9. Bates PJ, MacDonald J, Wang CY, Mah J, Liang H (2003) Vibration welding nylon 66 - part I experimental study. J Thermoplast Compos Mater 16:101-118. doi:10.1106/089270503025869
10. Chung YM, MusaR K (2008) Morphology of PA-6 vibration welded joints and its effect on weld strength. Polym Eng Sci 48:240-248. doi:10.1002/pen.20830

11. Weglowska A (2014) Effect of vibration welding parameters on the quality of joints made of polyamide 66. Polimery 59:239-245. doi: 10.14314/polimery.2014.239

12. Weglowska A, Pietras A (2012) Influence of the welding parameters on the structure and mechanical properties of vibration welded joints of dissimilar grades of nylons. Arch Civil Mech Eng 12:198-204. doi:10.1016/j.acme.2012.03.009

13. Bates PJ, Dyck C, Osti M (2004) Vibration welding of nylon 6 to nylon 66. Polym Eng Sci 44:760-771. doi:10.1002/pen.20068

14. Tsang KY, DuQuesnay DL, Bates PJ (2008) Fatigue properties of vibration-welded nylon 6 and nylon 66 reinforced with glass fibers. Compos Part B 39:396-404. doi:10.1016/j. compositesb.2007.01.012

15. Lockwood KT, Zhang Y, Bates PJ, DuQuesnay DI (2014) Effect of temperature on fatigue strength of vibration welded and unwelded glass reinforced nylon 6. Int J Fatigue. doi:10.1016/j.ijfatigue.2014. 03.017

16. Information materials of Bielomatic Company (2011)

17. Potente H, Heim HP, Schnieders J, Bussing M (2006) Quality increase and fine fluff avoidance in vibration welding. ANTEC, Conference Proceedings, Charlotte, pp 2241-2245

18. Potente H, Schnieders J, Bussing M (2006) Minimising abrasion and fine fluff in vibration welding. Weld World 50:65-70. doi:10.1007/ BF03263434

19. Rattke M, Natrop J (2007) Infrared heating in plastics welding technology. Join Plast 1:58-63

20. Dai X Y, Park G, Kontopoulou M(2004) Force measurements during vibration welding of nylon 66. Annual Technical Conference ANTEC, 1137-1141

21. Wegglowski MS (2008) Modelling and analysis of arc light spectrum in GMAW. Weld J 87:212-218

22. Weglowski MS (2009) Measurement of arc light spectrum in the MAG welding method. Metrol Meas Syst 16:143-159

23. www.ensinger.pl (2011) 